\title{
(2) OPEN ACCESS \\ Biomarker-assessed passive smoking in relation to cause-specific mortality: pooled data from 12 prospective cohort studies comprising 36 584 individuals
}

\author{
Elisabeth Kvaavik $\odot,{ }^{1}$ Aage Tverdal $\odot{ }^{2} \mathrm{G}$ David Batty $\oplus^{3}$
}

\begin{abstract}
- Additional material is published online only. To view, please visit the journal online (http://dx.doi.org/10.1136/ jech-2020-215398).
\end{abstract}

'Department of Alcohol, Tobacco and Drugs, Norwegian Institute of Public Health, Oslo, Norway ${ }^{2}$ Norwegian Institute of Public Health, Oslo, Norway

${ }^{3}$ Department of Epidemiology and Public Health, University College London, London, UK

Correspondence to Dr Elisabeth Kvaavik, Department of Alcohol, Tobacco and Drugs, Norwegian Institute of Public Health, Oslo N-0213, Norway;

Elisabeth.Kvaavik@fhi.no

Received 21 August 2020 Revised 30 December 2020 Accepted 16 January 2021 Published Online First 4 February 2021

\begin{abstract}
Aims While investigators have typically quantified the health risk of passive (secondhand) smoking by using self-reported data, these are liable to measurement error. By pooling data across studies, we examined the prospective relation of a biochemical assessment of passive smoking, salivary cotinine, with mortality from a range of causes.

Methods We combined data from 12 cohort studies from England and Scotland initiated between 1998 and 2008. A total of 36584 men and women aged 16-85 years of age reported that they were non-smoking at baseline, provided baseline salivary cotinine and consented to mortality record linkage.

Results A mean of 8.1 years of mortality follow-up of 36584 non-smokers (16 792 men and 19792 women) gave rise to 2367 deaths ( 775 from cardiovascular disease, 779 from all cancers and 289 from smokingrelated cancers). After controlling for a range of covariates, a $10 \mathrm{ng} / \mathrm{mL}$ increase in salivary cotinine was related to an elevated risk of total (HRs; $95 \% \mathrm{CI})(1.46$; 1.16 to 1.83$)$, cardiovascular disease $(1.41 ; 0.96$ to 2.09), cancer (1.49; 1.00 to 2.22 ) and smoking-related cancer mortality (2.92; 1.77 to 4.83$)$.
\end{abstract}

Conclusions Assessed biomedically, passive smoking was a risk factor for a range of health outcomes known to be causally linked to active smoking.

\section{INTRODUCTION}

Although there have been substantial secular declines in smoking prevalence in adults in the western world in recent years, more than 7 million UK adults still engage in the habit, ${ }^{1}$ and there are estimated to be over 1 billion smokers worldwide. ${ }^{2}$ Consequently, although perhaps overestimates owing to the implementation of smoking bans in bars and restaurants in the $\mathrm{UK}^{3}$ in 2002, up to $13 \%$ of non-smokers reported being passively exposed to tobacco smoke in the home and $10 \%$ in the workplace. ${ }^{4}$

Globally each year more than 1 million individuals are thought to die from passive smoking, also known as secondhand smoking or environmental tobacco smoke. ${ }^{2}$ Such estimates are based on the numerous studies that have explored the health consequences of passive smoking with the suggestion that it is linked to most diseases known to be caused by active smoking, including cardiovascular disease and selected cancers. ${ }^{5}$ In these studies, investigators have typically relied on self-reported measures of passive smoking, raising concerns regarding reporting error. Furthermore, some of the evidence is based on case-control studies ${ }^{6-9}$ raising methodological concerns regarding reporting bias and reverse causality. While more recent reports have used biomarkers of passive smoking in analyses of mortality or morbidity cohort data, ${ }^{10-12}$ interpretation of these findings is hampered by the small size of most studies. Accordingly, we pooled data for non-smokers across 12 cohort studies to explore the relation of salivary cotinine, a widely used indicator of passive smoking, ${ }^{13}$ with the risk of cause-specific mortality.

\section{METHODS}

The Scottish Health Survey (SHS) ${ }^{14}$ and the Health Survey for England (HSE) ${ }^{15}$ are independent, nearidentical, cross-sectional, general population-based studies examining individuals living in households in each country. Described extensively elsewhere ${ }^{16-18}$ in the present analyses, study members were aged 16-85 years at recruitment and were subsequently linked to a national cause-of-death registry. For the present analyses, we used only those surveys with salivary cotinine data (SHS 1998 and 2003; HSE 1997-2004, 2007 and 2008). Participants gave full consent.

\section{Assessment of active and passive smoking}

Data on self-reported smoking were collected using standard enquiries (current, former and never smokers). For the cotinine assessment, a dental roll saturated with participant saliva was later analysed using a gas chromatographic method (Hewlett Packard HP5890) with a lower limit of detection of $0.1 \mathrm{ng} / \mathrm{mL}$ (levels below $0.1 \mathrm{ng} / \mathrm{mL}$ are regarded as being undetectable). ${ }^{19}$ In the $2008 \mathrm{HSE}$, this methodology was changed to a liquid chromatography-tandem mass spectrometry method, ${ }^{19}$ but the two methods produce comparable results. ${ }^{20} 21$ Internal quality control is described elsewhere. ${ }^{22}$ Average coefficient of variation is $3.9 \%$ in the range $1-1000 \mathrm{ng} / \mathrm{mL} .^{19}{ }^{22}$ Salivary cotinine, a metabolite (and anagram) of nicotine, is shown to be a valid marker of tobacco smoke exposure in the previous 72 hours and to show sufficiently high specificity and sensitivity for the purposes of population-based research. ${ }^{132324}$ 


\section{Assessment of confounders}

Self-reported confounding factors were sex, age, survey, socioeconomic status, long-standing illness and alcohol consumption. Study member occupation was coded according to the Registrar General classification for social class, ${ }^{25}$ a six-level indicator of socioeconomic status in which a lower score indicates greater prestige. Respondents reported if they suffered from a long-standing illness and their level of alcohol consumption (consumption at least five occasions per week was denoted as high). Long-standing illness was defined as 'long-standing illness, disability or infirmity' and the time period referred to was 'anything that has troubled you over a period of time, or that is likely to affect you over a period of time', with the response alternatives: no, yes or don't know.

\section{Ascertainment of cause of death}

Cause of death was based on certification and coded according to the International Classification of Diseases (10th revision; ICD-10). ${ }^{26}$ We generated outcomes for mortality from allcauses, cardiovascular disease (ICD codes I01-I99) and all cancers combined (C00-D48). Based on existing evidence, ${ }^{27} 28$ we also denoted smoking-related cancers as C01-C16, C22, C25, C30.0, C31, C32, C34, C53, C64-C67, C68.0, C68.1, C68.8, C68.9 and C92. These cancers are shown to have an established relation with smoking and consist of cancers in the lung, stomach, pancreas, bladder, upper aerodigestive, kidney, myeloid leukaemia and liver. ${ }^{2728}$

\section{Statistical analyses}

Altogether, 142150 men and women were surveyed in 12 studies. Of these, 61740 provided a salivary cotinine and 57 284 gave consent to use their data. After omitting self-reported smokers $(n=12$ 862), participants with a cotinine value at or above $15 \mathrm{ng} / \mathrm{mL}$ (self-reported non-smokers with salivary cotinine $\geq 15.00 \mathrm{ng} / \mathrm{mL}$ were regarded as deceivers) $(\mathrm{n}=1$ $971),{ }^{2930}$ and those without complete covariate data $(\mathrm{n}=5867)$, 36584 study members (19 792 women) remained. This was our analytical sample.

Having ascertained that the proportional hazards assumption had not been violated, we used Cox proportional hazards regression models ${ }^{31}$ to estimate HRs with $95 \%$ CIs to summarise the relationship between salivary cotinine level and risk of death. In these analyses, calendar time (months) was the time scale, with censoring taking place on date of death or end of mortality surveillance (15 February 2011 for HSE and 31 December 2009 for the SHS), whichever came first. As there was no effect modification of the cotinine-death relation by sex or age, we combined men, women and all ages in the analyses and adjusted for sex and age in addition to other covariates. We included survey year as fixed effects in the models. We entered two sets of covariates into the models: sex and age (comparator model); and sex, age, survey year, social class, frequency of alcohol use and long-standing illness. The mkspline procedure in STATA produced multivariable-adjusted spline curves for any death and deaths from cardiovascular disease, total cancer and smokingrelated cancer. We carried out all analyses using Stata V.14.1.32

\section{RESULTS}

Age, sex, social status, self-reported illness and former smoking varied with cotinine level such that study members in the lowest cotinine tertile were older, and there was a lower proportion of men, manual workers and former smokers relative to the higher tertiles (table 1). Furthermore, higher proportions of participants in the lowest tertile reported long-standing illness than in the other groups. There was no difference in the prevalence of high alcohol intake according to cotinine categories. Salivary cotinine levels varied with study years, with lower levels after the smoking ban was implemented in UK in 2006 (results not shown). Cotinine levels varied substantially across smoking categories, with self-reported active smokers having the highest cotinine levels (see figure 1).

The 36584 non-smoking study participants were followed up for a mean of 8.1 years (range: $0.02-13.1$ years) giving rise to 2365 deaths (out of which 775 deaths were from cardiovascular disease, 779 were from all cancers and 289 were from smokingrelated cancers). In table 2, we show the relation of salivary cotinine with mortality risk. The highest level of cotinine was associated with elevated rates of death from all-causes (HR; $95 \%$ CI: $1.25 ; 1.14$ to 1.38$)$ cardiovascular disease $(1.33 ; 1.13$ to 1.58$)$ and all cancers combined $(1.20 ; 1.01$ to 1.42$)$, with the strongest effect apparent for smoking-related cancers $(1.57 ; 1.19$ to 2.06). There was some attenuation of risk after adjustment for multiple cofounding factors, although statistical significance at conventional levels was retained in most analyses. Mortality by continuous cotinine showed a similar pattern with elevated risk of death from any cause, cardiovascular disease, all cancers and smoking-related cancer. Additional analysis for total mortality adjusted for physical activity, blood pressure, mental health and self-assessed general health was carried out. However, these adjustments did not change the result.

Figure 2 shows the spline curves for death from all-causes, cardiovascular disease, all cancers combined and smoking-related

Table 1 Baseline characteristics by salivary cotinine level in 36584 non-smokers

\begin{tabular}{|c|c|c|c|c|c|}
\hline & \multirow[b]{2}{*}{ All $(0-14.9)$} & \multicolumn{3}{|c|}{ Salivary cotinine $(\mathrm{ng} / \mathrm{mL})$ tertiles } & \multirow[b]{2}{*}{$P$ value for difference across tertiles } \\
\hline & & Low $(0-0.1)$ & Middle (>0.1-0.5) & High $(>0.5-14.9)$ & \\
\hline $\mathrm{N}$ & 36584 & 13320 & 11471 & 11793 & \\
\hline Age (years) & & 51.9 & 48.9 & 46.0 & $<0.001$ \\
\hline Cotinine $(\mathrm{ng} / \mathrm{mL})$ & & 0.03 & 0.32 & 2.01 & $<0.001$ \\
\hline Manual social class & & 30.7 & 36.0 & 46.5 & $<0.001$ \\
\hline Long-standing illness & & 46.4 & 44.7 & 43.8 & $<0.001$ \\
\hline High alcohol intake & & 18.3 & 17.3 & 18.5 & 0.06 \\
\hline Formers smokers & & 30.9 & 31.2 & 34.0 & $<0.001$ \\
\hline
\end{tabular}


400

364.6

350

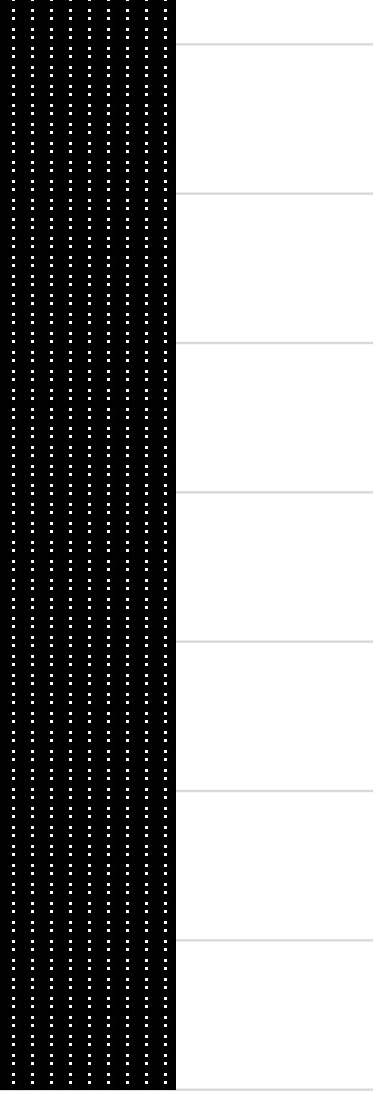

0

0.3

0.4

116.3

100

50

Never smokers III Former smokers 310 cigarettes per day $\$ 10$ to 19 cigarettes per day

20+ cigarettes per day

Figure 1 Median salivary cotinine levels by self-reported smoking status. N=51 417 .

cancers in which we illustrate thresholds of risk in relation to cotinine levels. The curves indicate that there is an increase in mortality from all causes, cancer and cardiovascular disease with increasing cotinine levels with a plateau at around $2 \mathrm{ng} / \mathrm{mL}$ such that no association seems to be present thereafter. For smokingrelated cancer, this inflection is less apparent.

\section{DISCUSSION}

The main finding of the present analyses was that salivary cotinine, our biomarker of passive smoking, was associated with elevated rates of mortality from various causes, effects that was independent of selected confounding variables. The magnitude of these relationships was, as anticipated, lower than those apparent for active smoking (online supplemental file).

\section{Comparison with published studies}

As discussed, few studies of mortality risk have used biomarker measurements to capture exposure to passive smoking. That different cotinine measures have been deployed-urine, saliva and blood ${ }^{101233} 34$ - complicates synthesis, although correlations among the passive smoking indicators is high. Weak and modest associations have been reported for cotinine indices in relation to total mortality ${ }^{12} 3334$ and lung cancer, ${ }^{33}$ while associations between cotinine level and deaths from heart disease and cardiovascular disease vary. ${ }^{33-35}$ The shape of the cotinine-cardiovascular disease association in the current study suggests a threshold at low doses after which there is no distinct increase in mortality. This observation seems to accord with extant studies. ${ }^{12} 33-35$ The observed lower threshold in cancer mortality may indicate that low but detectable levels of cotinine are not carcinogenic. An explanation of the observed threshold for CVD and cancer mortality needs further investigation. By contrast, the relation between cotinine and cancers ascribed to passive smoking was incremental across the cotinine continuum.

\section{Study strengths and limitations}

A reliance on self-report of any characteristic may be problematic as interpretation may be hampered by socially desirable responses, and smoking is no exception. ${ }^{36} 37$ Our study has the advantage of having biological measurement of passive smoking, salivary cotinine, which correlates highly with cotinine in blood ${ }^{23}$ and may even offer higher sensitivity than cotinine from urine and serum. ${ }^{13}$ In addition, our study has an objective health outcome, that is, cause of death was based on certification 
Table 2 HRs $(95 \% \mathrm{Cl})$ for the association between salivary cotinine and mortality in 36584 non-smokers

\begin{tabular}{|c|c|c|c|c|c|}
\hline \multirow[b]{2}{*}{ Salivary cotinine $(\mathrm{ng} / \mathrm{mL})$} & \multicolumn{3}{|c|}{ Salivary cotinine } & \multirow[b]{2}{*}{$P$ value for trend } & \multirow{2}{*}{$\begin{array}{l}\text { Continuous salivary cotinine } \\
\text { Per } 10 \mathrm{ng} / \mathrm{mL} \text { increase }\end{array}$} \\
\hline & Tertile 1 (low) & Tertile 2 & Tertile 3 & & \\
\hline Range & $0-0.1$ & $>0.1-0.5$ & $>0.5-14.9$ & & \\
\hline Mean & 0.03 & 0.32 & 2.01 & & \\
\hline \multicolumn{6}{|l|}{ Total mortality } \\
\hline No. of deaths & 814 & 701 & 850 & & \\
\hline Age and sex adjusted & 1 (Ref) & $0.95(0.86$ to 1.05$)$ & $1.25(1.14$ to 1.38$)$ & 0.001 & $1.74(1.40$ to 2.18$)$ \\
\hline Multiple adjusted* & 1 & 0.91 (0.83 to 1.01$)$ & $1.18(1.07$ to 1.30$)$ & 0.002 & $1.46(1.16$ to 1.83$)$ \\
\hline \multicolumn{6}{|c|}{ Cardiovascular disease mortality } \\
\hline No. of deaths & 264 & 227 & 284 & & \\
\hline Age and sex adjusted & 1 & $0.97(0.81$ to 1.16$)$ & 1.33 (1.13 to 1.58$)$ & 0.001 & 1.78 (1.21 to 2.61$)$ \\
\hline Multiple adjusted* & 1 & $0.91(0.76$ to 1.09$)$ & $1.22(1.03$ to 1.45$)$ & 0.025 & $1.41(0.96$ to 2.09$)$ \\
\hline \multicolumn{6}{|l|}{ Cancer mortality } \\
\hline No. of deaths & 275 & 216 & 288 & & \\
\hline Age and sex adjusted & 1 & $0.85(0.71$ to 1.01 & 1.20 (1.01 to 1.42$)$ & 0.036 & 1.73 (1.17 to 2.55$)$ \\
\hline Multiple adjusted* & 1 & 0.83 (0.69 to 0.99$)$ & $1.13(0.95$ to 1.34$)$ & 0.175 & 1.49 (1.00 to 2.22$)$ \\
\hline \multicolumn{6}{|c|}{ Smoking-related cancer mortality } \\
\hline No. of deaths & 90 & 75 & 124 & & \\
\hline Age and sex adjusted & 1 & $0.90(0.66$ to 1.23$)$ & 1.57 (1.19 to 2.06$)$ & 0.001 & 3.20 (1.95 to 5.22$)$ \\
\hline Multiple adjusted* & 1 & $0.88(0.64$ to 1.19$)$ & 1.43 (1.08 to 1.89$)$ & 0.010 & 2.92 (1.77 to 4.83$)$ \\
\hline
\end{tabular}

${ }^{*}$ Adjusted for sex, age, survey, social class, long-standing illness and alcohol intake.

and coded according to the ICD-10. ${ }^{26}$ However, while salivary cotinine may capture exposure in all contexts, it has a half-life of $20 \mathrm{~h}$ and will such only index recent passive smoking. There is also some individual variability in nicotine metabolism and elimination. ${ }^{102324}$ These conditions might have caused some misclassification of smokers and non-smokers. That salivary cotinine levels correlated strongly with self-reported active smoking status such that there was a marked difference between smokers and non-smokers (figure 1) gives us confidence in our results for passive smoking.

There are some study limitations. Passive and active smoking were captured at a single point in time, and this may have resulted
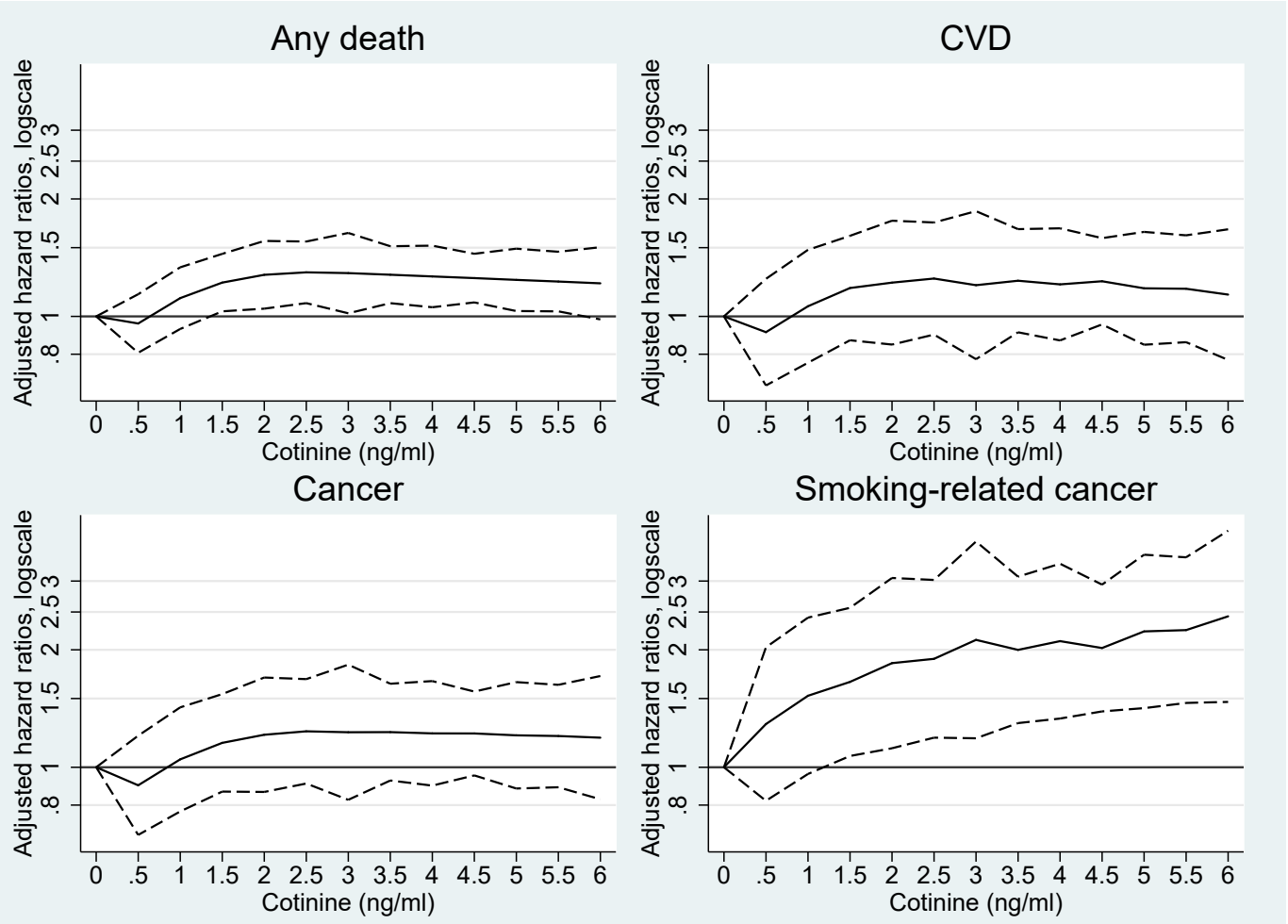

Figure 2 Deaths from any cause, cancer, cardiovascular disease (CVD) and smoking-related cancer by salivary cotinine level (ng/mL). Solid line represents HR, and dotted line represents $95 \%$ Cls. 
in some degree of misclassification of the study participants who changed habits during follow-up, during the more than decadelong period of baseline data collection (1997-2008), smoking prevalence and hence passive smoking decreased considerably. ${ }^{38}$ It is likely that this misclassification was not systematic with respect to the outcomes under study, and as such, we have underestimated the health risks of passive smoking, possibly more for cancers due to a longer lag between exposure and outcome. Residual confounding is a perennial limitation in observational analyses, and our study is no exception. Lastly, the use of cotinine, the most common biomarker of passive smoking, is not without its challenges. Other exposures that may influence cotinine level such as nicotine vapour from room surfaces, clothing and dust, some foods, smokeless tobacco products (snus) and nicotine replacement therapy were not captured in the present study and were not taken into account. However, we did exclude study members because their cotinine levels were too high for them to be realistically classified as non-smokers. It is possible that at least some of these people had used nicotine products other than cigarettes.

In conclusion, our study supports an association between objectively ascertained secondhand smoking and mortality from any death, cardiovascular disease and smoking-related cancers. The apparent threshold effects for some of these relationships require further exploration.

Data are available in a public, open access repository. ${ }^{39}$

Contributors EK: conception and design of the work, acquisition and interpretation of data and drafting the work. AT: analysis and interpretation of data and revising the work critically for important intellectual content. GB: conception and design of the work, acquisition and interpretation of data and revising the work critically for important intellectual content. All authors have final approved this version of the work to be published and agreed to be accountable for all aspects of the work in ensuring that questions related to the accuracy or integrity of any part of the work are appropriately investigated and resolved.

Funding The authors have not declared a specific grant for this research from any funding agency in the public, commercial or not-for-profit sectors.

Competing interests None declared.

Patient consent for publication Not required.

Ethics approval Ethical approval was provided by the London Research Ethics Council.

\section{What is already known on this subject}

- Passive smoking appears to be related to a range of chronic diseases.

- With studies almost exclusively relying on self-reports of passive smoking, the magnitude of relationship may have been biased.

- There are also very few prospective cohort studies in this context which, in the absence of clinical trials, provide the best evidence of a causal link.

\section{What this study adds}

- In the present context, this multicohort study is the largest to date with data on a biomarker of passive smoking.

- In non-smokers, salivary cotinine above a threshold of $0.5 \mathrm{ng} /$ $\mathrm{mL}$ was associated with a $20 \%-40 \%$ higher rate of death from all-causes, cardiovascular disease and smoking-related cancers.
Provenance and peer review Not commissioned; externally peer reviewed.

Data availability statement Data are available in a public, open access repository. Data can be downloaded from the UK data archive (www.data-archive. ac.uk).

Supplemental material This content has been supplied by the author(s). It has not been vetted by BMJ Publishing Group Limited (BMJ) and may not have been peer-reviewed. Any opinions or recommendations discussed are solely those of the author(s) and are not endorsed by BMJ. BMJ disclaims all liability and responsibility arising from any reliance placed on the content. Where the content includes any translated material, BMJ does not warrant the accuracy and reliability of the translations (including but not limited to local regulations, clinical guidelines, terminology, drug names and drug dosages), and is not responsible for any error and/or omissions arising from translation and adaptation or otherwise.

Open access This is an open access article distributed in accordance with the Creative Commons Attribution Non Commercial (CC BY-NC 4.0) license, which permits others to distribute, remix, adapt, build upon this work non-commercially, and license their derivative works on different terms, provided the original work is properly cited, appropriate credit is given, any changes made indicated, and the use is non-commercial. See: http://creativecommons.org/licenses/by-nc/4.0/.

\section{ORCID iDs}

Elisabeth Kvaavik http://orcid.org/0000-0003-4570-0265

Aage Tverdal http://orcid.org/0000-0002-2909-5678

G David Batty http://orcid.org/0000-0003-1822-5753

\section{REFERENCES}

1 Office for National Statistics, UK. Adults smoking habits in the UK: 2018. Available: https://www.ons.gov.uk/peoplepopulationandcommunity/healthandsocialcare/heal thandlifeexpectancies/bulletins/adultsmokinghabitsingreatbritain/2018 [Accessed 22 Jan 2020].

2 World Health Organization. Tobacco. Fact sheet, 2019. Available: https://www.who. int/news-room/fact-sheets/detail/tobacco [Accessed 22 Jan 2020].

3 Haw SJ, Gruer L. Changes in exposure of adult non-smokers to secondhand smoke after implementation of smoke-free legislation in Scotland: national cross sectional survey. BMJ 2007;335:549.

4 Jamrozik K. Estimate of deaths attributable to passive smoking among UK adults: database analysis. BMJ 2005:330:812.

5 Öberg M, Jaakkola MS, Woodward A, et al. Worldwide burden of disease from exposure to second-hand smoke: a retrospective analysis of data from 192 countries. Lancet 2011;377:139-46.

6 Wartenberg $\mathrm{D}$, Calle EE, Thun MJ, et al. Passive smoking exposure and female breast cancer mortality. J Nat/ Cancer Inst 2000;92:1666-73.

7 Eisner MD, Wang Y, Haight TJ, et al. Secondhand smoke exposure, pulmonary function, and cardiovascular mortality. Ann Epidemiol 2007;17:364-73.

8 Cardenas VM, Thun MJ, Austin H, et al. Environmental tobacco smoke and lung cancer mortality in the American cancer Society's cancer prevention study. II. Cancer Causes Control 1997;8:57-64. [Erratum in: Cancer Causes Control 1997:8:675].

9 Jiang J, Pang $\mathrm{H}$, Liu B, et al. Effects of active, passive, and combined smoking on cervical cancer mortality: a nationwide proportional mortality study in Chinese urban women. Cancer Causes Control 2015:26:983-91.

10 Batty GD, Gale CR, Jefferis B, et al. Passive smoking assessed by salivary cotinine and self-report in relation to cause-specific mortality: 17-year follow-up of study participants in the UK health and lifestyle survey. J Epidemiol Community Health 2014;68:1200-3.

11 Wulaningsih W, Serrano FEC, Utarini A, et al. Smoking, second-hand smoke exposure and smoking cessation in relation to leukocyte telomere length and mortality. Oncotarget 2016;7:60419-31.

12 Lu L, Mackay DF, Pell JP. Secondhand smoke exposure and risk of incident peripheral arterial disease and mortality: a Scotland-wide retrospective cohort study of 4045 non-smokers with cotinine measurement. BMC Public Health 2018;18:348.

13 Connor Gorber S, Schofield-Hurwitz S, Hardt J, et al. The accuracy of self-reported smoking: a systematic review of the relationship between self-reported and cotinineassessed smoking status. Nicotine Tob Res 2009:11:12-24.

14 Gray L, Batty GD, Craig P, et al. Cohort profile: the Scottish health surveys cohort: linkage of study participants to routinely collected records for mortality, hospital discharge, cancer and offspring birth characteristics in three nationwide studies. Int J Epidemiol 2010:39:345-50

15 Mindell J, Biddulph JP, Hirani V, et al. Cohort profile: the health survey for England. Int J Epidemiol 2012;41:1585-93.

16 Batty GD, Russ TC, Stamatakis E, et al. Psychological distress in relation to site specific cancer mortality: pooling of unpublished data from 16 prospective cohort studies. BMJ 2017;356:j108.

17 Russ TC, Stamatakis E, Hamer M, et al. Association between psychological distress and mortality: individual participant pooled analysis of 10 prospective cohort studies. BMJ 2012;345:e4933. 
18 de Mestral C, Bell S, Stamatakis E, et al. Testing differential associations between smoking and chronic disease across socioeconomic groups: pooled data from 15 prospective studies. Epidemiology 2019;30:48-51.

19 Feyerabend C, Russell MA. A rapid gas-liquid chromatographic method for the determination of cotinine and nicotine in biological fluids. J Pharm Pharmacol 1990;42:450-2.

20 Bernert JT, Jacob P, Holiday DB, et al. Interlaboratory comparability of serum cotinine measurements at smoker and nonsmoker concentration levels: a round-robin study. Nicotine Tob Res 2009;11:1458-66.

21 Craig R, Mindell J, Hirani V, eds. Health Survey for England 2008. Vol. 2 - Methods and Documentation. Leeds: NHS Information Centre, 2009.

22 Scottish Health Survey 2012 - Volume 2 Technical Report. Available: https://www.gov scot/publications/scottish-health-survey-2012-volume-2-technical-report/pages/22/ [Accessed 21 Nov 2020].

23 Benowitz NL. Cotinine as a biomarker of environmental tobacco smoke exposure. Epidemiol Rev 1996;18:188-204.

24 Avila-Tang E, Al-Delaimy WK, Ashley DL, et al. Assessing secondhand smoke using biological markers. Tob Control 2013;22:164-71.

25 Office for National Statistics. National Statistics - Socioeconomic classification scheme. London, UK: Office for National Statistics, 2010. https://www.ons.gov.uk/ methodology/classificationsandstandards/otherclassifications/thenationalstatisticssoc ioeconomicclassificationnssecrebasedonsoc2010

26 World Health Organization. International statistical classification of diseases and related health problems 10 th revision volume 2 instruction manual. 5th edn, 2016. ISBN: 978924 154916 5. https://icd.who.int/browse10/Content/statichtml/ ICD10Volume2_en_2016.pdf

27 IARC Monographs on the Evaluation of Carcinogenic Risks to Humans. Tobacco smoke and involuntary smoking, Lyon, France, 2004. Available: https://publications.iarc.fr/BookAnd-Report-Series/larc-Monographs-On-The-Identification-Of-Carcinogenic-Hazards-ToHumans/Tobacco-Smoke-And-Involuntary-Smoking-2004 [Accessed 1 March 2020].
28 Batty GD, Kivimaki M, Gray L, et al. Cigarette smoking and site-specific cancer mortality: testing uncertain associations using extended follow-up of the original Whitehall study. Annals of Oncology2008;19:996-1002.

29 Whincup PH, Gilg JA, Emberson JR, et al. Passive smoking and risk of coronary heart disease and stroke: prospective study with cotinine measurement. BMJ 2004;329:200-5

30 Jarvis MJ, Tunstall-Pedoe $\mathrm{H}$, Feyerabend C, et al. Comparison of tests used to distinguish smokers from nonsmokers. Am J Public Health 1987;77:1435-8.

31 Cox DR. Regression models and Life-Tables. J R Stat Soc Ser B 1972;34:187-202.

32 Stata Press. Survival analysis reference manual. Texas: College Station, 2019. ISBN: 978-1-59718-297-3. http://www.stata.com/bookstore/survival-analysis-referencemanual/

33 Flores RM, Liu B, Taioli E. Association of serum cotinine levels and lung cancer mortality in non-smokers. Carcinogenesis 2016;37:1062-9.

34 Gallo V, Neasham D, Airoldi L, et al. Second-Hand smoke, cotinine levels, and risk of circulatory mortality in a large cohort study of never-smokers. Epidemiology 2010:21:207-14.

35 Rostron B. Mortality risks associated with environmental tobacco smoke exposure in the United States. Nicotine Tob Res 2013;15:1722-8.

36 Alamar B, Glantz SA. Effect of increased social unacceptability of cigarette smoking on reduction in cigarette consumption. Am J Public Health 2006;96:1359-63.

37 Fisher MA, Taylor GW, Shelton BJ, et al. Sociodemographic characteristics and diabetes predict invalid self-reported non-smoking in a population-based study of U.S. adults. BMC Public Health 2007;7:33.

38 Office for National Statistics, UK. Smoking and drinking among adults 2009, in general lifestyle survey 2009. Newport, South Wales: National Statistics, 2011. https:// sp.ukdataservice.ac.uk/doc/6716/mrdoc/pdf/2009_report.pdf

39 UK data Archive, University of Essex, UK. Available: www.data-archive.ac.uk 